\title{
Self-disturbance in the National Medium after 36 Years of the Islamic Revolution
}

\author{
Ali Asghar Amini Dehaghi ${ }^{1}$ \\ ${ }^{1}$ Islamic Republic of Iran Broadcasting, Valiasr Street, Tehran, Iran \\ Correspondence: Ali Asghar Amini Dehaghi, Islamic Republic of Iran Broadcasting, Valiasr Street, Tehran, Iran. \\ E-mail: Amini779@yahoo.com
}

$\begin{array}{lc}\text { Received: December 29, } 2015 & \text { Accepted: January 15, } 2016 \quad \text { Online Published: February 23, } 2016 \\ \text { doi:10.5539/ass.v12n3p85 } & \text { URL: http://dx.doi.org/10.5539/ass.v12n3p85 }\end{array}$

URL: http://dx.doi.org/10.5539/ass.v12n3p85

\begin{abstract}
Self-disturbance of the Iranian national medium, after 36 years of the Islamic Revolution, could be due to the structural and software effects of the political-religious culture ruling the community. In particular, the structural effect of bureaucracy on the structural system of the national medium has created self-disturbance in this medium. The content and meaning of this medium is, more than any other thing, dominated by the traditional media such as mosques, Hossainies, clergymen, and the descendants of Imams Etc. which are mostly provided by religious clergymen. In addition, the presence of the clergy on top of the pyramid of power has caused the procedure of the national medium which moves based on the patterns of modernity to be manifested as its religious-traditional content and meaning being influenced by and against secularism. This is why the national medium, in spite of the lack of any serious domestic rival, is incapable of global competition in the field of plurality of Persian speaking media. As a result several factors arising from the cultural-religious as well as political spheres have provided self-disturbance in the Iranian national medium.
\end{abstract}

Keywords: national medium, traditional medium, bureaucratic culture, self-disturbance, communication process

\section{Introduction}

In the field of media communication, noise is a factor that can prevent effective transmission of the message through two approaches of channel and meaning (content). As a result a kind of disturbance emerges in the communication process of the medium that prevents the formation of a successful communication process from the sender of the Message to the receiver of the message. On the contrary it prevents the formation of proper feedback from the receiver toward the sender. (Blick \& Harwaldsen, 1378)

In the media, noise in channel provides more than anything else, structural-technological obstacles between the sender and the receiver of the message while noise in meaning is focused more than anything else on the message content problems in the communication process between the sender and the receiver, and does not allow the emergence of conceptually appropriate understanding.

Given these two major obstacles to understand the message, a third factor (self-disturbance) also arises in the medium that does not partly allow for the effectiveness of the message. Therefore, this communication obstacle in the medium is assumed to relate to the formation of the organizational-management system of the medium that will officiously lead to the production of disturbances in the process of communication between the sender and the receiver. More importantly, such an obstacle, appears on the basis of the cultural-ideological context of the community within the software context of the medium itself and does not allow the emergence of what is pursued by the authors of the message regarding the effectiveness toward the audience in a national medium such as the Iranian national medium after 36 of the Islamic Revolution. (Azdanlo, 1386)

This could be considered as being caused by several factors such as sociocultural, especially political differences in the lower strata of the community who is unwittingly manifested in the national medium.

Thereby the communication processes, particularly in the national medium, are inevitably influenced by the political, ideological, and religious climate in terms of software. However, the influence of Iran's national interests as well as ideals on the national medium not only lacks appropriateness in terms of software as observed in modern media structures, but also has turned the trend of the national medium within the internal system to self-disturbance; thus what authors of the message are seeking to convey is in contrast with what is 
happening in audience.

Among the factors leading to self-disturbance in the national medium of the Islamic Republic of Iran (IRIB) is a structural issue that is discussed at the administrative level since in the Iranian bureaucratic culture, the distance between the staff (the head of the organization) and the line (the operational front and facing the audience) is too far so that the plurality of micro as well as macro management in between the staff and line areas, prevent the facilitation of message-management and even the feedback of the line from the staff, thus when a message is sent by the president of the national medium to the line that is fully exposed to the audience and public opinion, it completely melts like a snowball halfway through under the interpretation process of the multiplicity of middle level managers, although personal tastes and benefits of middle level managers' interpretation of the message of the president of the organization must be considered. As a result, the line that receives the message for operationalization may likely receive a message that is not only diverted from the main purpose of the president of the organization or the staff of the national medium, but also may contradict the defined discourses of the president in the line. Therefore, the president of the national medium has to move beyond the defined system of the national medium in order to use his authority and inevitability ignore the legislated systematic management and directly interact with the line. He almost overlooks all administrative processes to explain his discourse to the line if ever the line can seek the habituated or conditioned condition to appropriately understand the President's message. As a result the president of the organization has to further justify and explain to convey his message to the line which contradicts his presidency as a strategist. This may be interpreted as meddling with the experts and may overshadow their personal identity which brings a great calamity in the area of expertise as the lack of accountability. (Nature of Iranian traditional nedia in political communication process)

Although in such relationships, in principle urgent inefficiencies in some areas of such organizations allow for the intervention of the president of the national medium to better understand the problem and to prevent the transformation of a professional crisis into an identity one, if the relationship of the head of the organization is to interact with the line out of the management system, normally a calamity emerges which is now transformed into an internal organizational crisis. Crises are not always associated with complexity and commotion; they gradually disrupt the defined foundations. This means that the staff, especially the president himself, creates the first violations as compliance with organizational expediency as well as authority becomes a priority. For example, a kind of quiet crisis starts when the IRIB President himself, owning to the fear of the seminary scholars or the religious who show unseasonable sensibilities to music hairless, inevitably has to directly supervise the production of musical clips. This is considered as insecurity of media activities of the organization the president of which does not trust it. This lack of trust suggests an internally latent crisis that will only address and punish the president of the national medium. The process of such interference by the president himself is so largely researched that could be investigated as a case study. More importantly, this process has inadvertently become a norm in the national medium so that even suggesting its abnormality in structure of the medium, cannot simply occur. (Iranian cultural Homeland)

Such action-reaction creates shortcuts between the staff and the line as secret corridors within the national medium. In sociology individuals who secretly operate in these corridors and follow economic incentives are called "secret deviants". It seems that in the national medium (IRIB), from the staff to the line, certain intentional and unintentional obstruction is secretly embedded in the body of the organization even the president of the national medium could not only distinguish it, but interference in this area leads to emergence of opposing processes against the national medium among the public opinion and creation of rumors.

The secret deviants are so strong that evidently presidents in various periods are proved to be blackmailed by them. Even secret deviants appear to have selected their own desirable managers.

Although the presidents' shortcuts have created secret corridors in the national medium, in reality it is considered a kind of self-disturbance in the process of communication of the national medium with the audience.

Generally, there are undeniably such disorders in organizational communication in advanced organizations, even in the developed countries. However such shortcuts and disturbances are embedded in various ways in the process of formulating strategies of the national medium.

Even beyond that, it allows for crisis management and in urgency it solves problems like a systematic reinforcement in a well-defined plan in the national medium. Especially a backup process is defined and systematically performs its primary activity.

Certainly one of these methods is to hold conferences. That is predictable by the public relations (PR) of any organization. In other words, the conference structure embedded in an organization acts as an urgent medicine for communication disorders. Normally due to the lack of integrity, the lack of foresight or unpredictable events, 
systems embed urgent conferences to prevent or resolve the disturbance in the process of organizational communication. Annual conferences as the media horizon to justify the goals of the national medium for senior managers of the national medium, suggest the dominance of the urgent management system over the national medium. If conferences are to be defined to play their urgent role in resolving the disturbance or anticipate the disturbance in the organizational and inter-organizational communication process, systematic PR systems should predict and manage them, although such assessments are defined to be out of the PR system. This mostly relates to the PR's lack of independence as one of the functions of PR is to establish a relationship between the organization and its audience, while the national medium due to communication with the public opinion wrong imagines that it can play a the role in this regard, while identifying the type of PR relationship and totality of the national medium are unwittingly mixed in a wrong way, since the nature of relations with the PR and the nature of the relations with the national medium itself are so differently assessed that so far no action regarding the evaluation of this issue is seen either in the national media or its PR.

The second self-disturbance process is related to the vertical management organization of the national medium which is influenced by the Iranian bureaucratic, as well as centralized culture to integrate part of the political forces which assist the organization in political discrepancies and competition. Therefore these individuals make efforts to fatten the (Blick \& Harwaldsen, 1378) media system based on their own sociopolitical status. As a result, after the Islamic Revolution of Iran, this process continued and caused swelling of the body of the national medium. Thus this not only intensifies the verticality of the administrative as well as bureaucratic system of the national medium, but is among self-disturbance factors in the national medium. The experience of such individuals has always imposed a fattening view on middle level managers since in such relationships the political and economic resources of such individuals become highly important. Therefore, not only decreases the quality of expertise but the man power thinks of gaining management rather than expertise.

Consequently the culture of acquiring power through management unwantedly shifts from specialization or the expert-oriented culture. The most important character of vertical management systems is to value and identity managers and administrative areas; while sometimes the identity of expertise and specialization is of value. Altogether, wherever expertise and specialization are valuable consequently false management acceptance decreases. Nowadays, each employee aspires to be a manager rather than an expert; this is the biggest self-disturbance factor. The national media should necessarily move in line with the horizontal management system for two main reasons:

1. Shortening the systematic relationship between staff and line.

2. Speed of the flow of information is a necessity for media management, especially the horizontal system increasingly help the management system's flow of information. Thus management organizations of the developed media such as BBC, VOA, CNN, FOX etc. comply with the horizontal management system. More importantly, the horizontal management system of the national medium, in addition to the speed of information flow and facilitation of the process of sending a message from the staff to the line, can provide changes through further supervisory processes by the president and the staff on the performance of the line without intermediaries and altering interpretations. Other factors of self-disturbance in the national medium which is very important than other factors is that the identity of the national media not only has caused internal self-disturbance and conflict but also aspects of the content in the media has been somewhat involved; however the discussion here is not concerned with the content issue. The modern structure of the national media is important. Traditional Shiite media not only interact but also strongly overlap with each other. Therefore, to enter this field it is necessary to briefly discuss firstly traditional media and then the relationship between these traditional media and the modern national medium especially IRIB, in terms of what effects conflicts and contradictions by this interaction as well as overlap may have on the self-disturbance in the national medium. (Formation of public opinion to update Rumors).

Traditional media are among the most important of communication means arising from Shi'ite religious beliefs and culture based on historical memory, signs, behaviors, norms, religious places such as mosques, pulpits (religious tribune), descendants of Imams, holy cities such as Qom and Mashhad and enjoy cultural-religious antiquity. Not only have they a pre-modern history but also are able to publicly both interact and overlap. The importance of these media in the Iranian religious culture is so high the Islamic Revolution Leader, Ayatollah Khomeini, in spite of restrictions on the lack of modern media such as radio and television, could engineer public opinions for a great revolution through such traditional media.

Above all, especially in the public domain he could effect on and communicate with the mass in this way. Perhaps if traditional media was not used as a communication tool by Ayatollah Khomeini the Islamic 
Revolution would never succeed. In other words, the Islamic Revolution was the arena of a contention between traditional media by religious revolutionaries and modern media by the ruling monarchy (Pahlavi II) which was consequently led to the triumph of the traditional media. In addition to being media, the traditional media has political, social, economic and cultural functions in the process of social interaction; however the scope of the current paper does not include the discussion of non-media functions of traditional media.

Although nowadays modern media has contributed to major events and ideas especially the production of knowledge to the philosophy of media, apart from their social-religious base among Iranian religious mass, the traditional media have particular regard in terms of the communication process, particularly the traditional media is based on the historical memory of Iranian Shi'ite community. Therefore the very historical memory has provided a mental unity between the clergy and the audience prior to the communication process. More importantly most traditional media not only have dual characteristics but are based on religious beliefs and enjoys a kind of emotional connection established between the two sides i.e. the transceiver.

Consequently, the process of satisfying and engineering public opinion by the sender in the form of a clergy as the imam of a mosque is well done and the sender is simply able to identify their audience's feedback. Therefore, the sender can quickly modify the message according to the feedback by the audience. In particular, there is an emotional- personal relationship between the clergy and each of the individuals in the mosque, a universalism which has maintained its supremacy despite the development of communication technology, so that it is also able to interact with modern media and even use them according to religious purposes. The presence of the internet in churches, temples and mosques suggests the authority of such media. The most important feature of traditional media (such as the historical-religious memory) first emerges from a kind of emotional relationship between the sender and the receiver as a pre-relationship. Initially a trust is developed between the two sides and then through such an emotional passage a new communication process is formed. In other words, traditional media initially produce a mental unity between the two sides and then the message is sent from the sender (as a mosque clergy) to the audience as the worshipers who first said their prayers behind him and listened to his words between the two prayers.

Although traditional-religious media have a variety of types in terms of formation and relationship process, they all share a principle that is being based on a historical-religious memory, and an emotional trust from religious belief which provides satisfaction, while this process may not be observed in modern media. Although modern philosophers and communication engineers are seeking to psychologically and technologically develop modern media, they may encounter certain sociological calamities. In particular, all users have become authors through modern media like the internet and the process of specialization, expertise and wisdom are tangled in the light of multitudes of messages and information that have been objectivized.

However, traditional media, especially the religious spectrum, not only help a revolution appear but also protect and guard it. For example mosques, mourning boards, religious rituals by the martyrdom of Hussain ibn Ali (third Shia Imam) were able to provide forces for battles in the imposed eight-year war, since traditional media in addition to joint religious, social, economic and security functions etc. could provide a strong network among a generation of young people for battlefield, a success which modern media such as press, radio and television of the Islamic Republic of Iran were unable to grasp even considering their religious nature. In particular, modern media such as the radio and television, due to financial and technical constraints arising from the war failed to satisfy people than traditional media. Although the national medium reflected the communication process of the national medium during the war, this apparently success is also assessed to arise from representations of traditional media.

However, nowadays the national medium, given the obviation of crises of financial as well as technical constraints etc. not only cannot appropriately benefits from traditional media, but the application and representation of traditional media is performed in a way which causes disturbance and weakens the communication process of the media to its audience. Thus, using traditional media not only satisfies the audience but provides contrasting results for the national medium so that it could be argued that the national medium has created self-disturbance through malapropos and non-engineered use of traditional media. The reflection of traditional media in a variety of ways in the national medium not only has provided self-disturbance in the communication process but also has weakened the functions of traditional media compared with the first and second decades of the Revolution. Hence, some solutions may be proposed for the problem:

1. Essentially modern media are influenced by religious, traditional messages, i.e. a religious message is more compatible with traditional media. For example, broadcasting a type of prayer (Komaile) from modern media such as TV may apparently look appropriate and admirable in believers' view. However, events may happen in 
such programs which may cause traditional media to weaken. Also audiences who like to say that prayer at a mosque but do not have appropriate situation at home may attend a virtual mosque which does not have required periphery to transfer the feelings of a real mosque. Whatever one tries to simulate the situation, there are some gaps in between about the prayers. What is important is to say a prayer with friends and Muslims at a public place in conjunction with interpersonal relationships influenced by the spiritual periphery of a mosque.

2. Mosques, in addition to being a medium, have other spiritual functions which are less observed with television at homes. If we need to attend at mosque to say Komaile prayers and observe emotional-spiritual generals we have to create a spiritual community at mosques together with a shared spiritual sense. This means that the main factor here is the mental unity between those who pray, feel spiritually and are close to God and the imam of the mosque. Not only this does not happen at a virtual mosque on TV but may also weaken the idea of attending at mosques. Saying prayer has certain spiritual and social conditions that necessarily are not observed in front of the TV since the feelings of the audience are not spiritually satisfied. Socially speaking, this resembles going to the cinema or watching a movie alone at home.

3. Generally clergymen as traditional-religious media in the national medium or in other words the broadcasting system are considered as being present as managers of the national medium or as high activists of the national medium. Consequently both clergymen and non-clergymen like to attend the national medium as the most expanding media of Iran. Clergymen always expect the national medium to make them appear on TV or radio as to preach Islamic beliefs. However the audience also may think so. The audience does not regard the name or title of the clergymen. All clergymen who preach on the TV are considered as under the same category of religious preachers. Therefore such programs, even with different designs, may unwittingly influence the message of the clergymen while religious programs should possess the process of defamiliarization, i.e. the audience should always find something new in the message sent by the clergymen as though it is the first time the message is heard. This prevents reputation and boredom of watching religious programs on the audience's side. This holds for attending holy places as well. Naturally a message must contain aesthetic or artistic signs to be conveyed appropriately. Otherwise it may destroy the opinion of the audience. The main feature of modern media is concerned with such signs which indirectly send the message. Thus religion in media should be associated with artistic and indirect frameworks in order to represent the issue of defamiliarization for the religious effect of the message.

4. Traditional media, in addition to the collective requirements, necessarily fill the gap between the sender and the receiver in the shortest time. Traditional media provide a face-to-face contact between the sender and the receiver as one of their most prominent feature. The longest distance between a clergyman and his audience in a mosque equals the width or length of the mosque. This is why the feedback is immediately received and an emotional connection is made between them due to shared knowledge and trust arising from the face-to-face contact. The clergymen are experienced enough to detect the type of feedback provided by the audience. Ali Shariati is among the most successful individuals who attracted his audience more than anything else through traditional media such as Husseinie Ershad in Tehran. He used such media to found an ideological revolution as a main influencing factor. In a one-hour speech, he devoted four hour receiving feedback provided by the audience so that the place turned to the largest front to combat the second Pahlavi.

5. The representation of traditional media, with more repetition that modern media can weaken traditional media, since the identity of traditional media is not bound to modern media. However, religious individuals need modern media, especially clergymen who grasped political positions after the Islamic Revolution. For example they need to participate in the Parliament elections. Thus although modern media may provide them with being elected as representatives, this may destroy their spiritual position. If traditional media come to affect the national medium they should speak with the language of art and also try to author the message behind the scene not to appear in front of camera to prevent the audience being saturated by repetitive messages. The audience should not be conditioned to the repetition of messages. People should knowingly be addressed to religious messages.

6. Normally, a message influences the audience in a communication process. Hence when the audience is watching Channel One, he/she is addressed by not only the main message but also the periphery messages before and after the main one. For example, when the audience receives messages with special recommendations to theosophy and piety and all of a sudden commercials are broadcasted which directly contrast the main message, the main message is destroyed. Non-engineered programs by experts of IRIB turn the audience's view as habitual but secular. More importantly the national medium is not a new-comer media to preach religion. It is worth noting that even many religious channels including Sunni and Shiite, with different or contradicting or even hostile views have attracted Persian speaking audiences. 
Overall, modern media such as the radio and television of Iran are controlled by the top of the pyramid of political, economic, cultural and especially religious power. The origination is not responsible to anyone but the religious-political ruler, i.e. Jurisconsult guardianship (Welayat Faghih). Generally, according to the defined ideology of the organization, orders are pointed by the supreme leader. In other words, the president of the national medium should always be cautious to not make any mistake when authoring a message.

Although message production is in the scope of the national medium, the process of engineering the message and macro-strategies is necessarily on the shoulders of the supreme leader. In other words, the president of the organization is supervised by the leadership system with macro-dimensions and macro-strategies and even software dimension. However, some other clergymen, dependent or independent from the leadership, may directly or indirectly influence over the process of message production.

Apart from the feedback by the community which assumes the religious function as the main function of IRIB. Whatever is not supposed to be in line with religious rules is considered in contrast with IRIB's opinion. Therefore, it is true that IRIB mostly regards feedback provided by the seminary scholars, prominent clergymen and finally some military institutions which have been involved in cultural as well as media activities in addition to their main military tasks rather than feedback provided by the public opinion. Therefore feedback by such influential parties who gained more access into the national medium after the imposed war led to establishment of some news media and TV channels, since they do not consider the functions of IRIB as appropriate to their revolutionary or religious values. This did not suffice for such an influence, but they considered it as necessary to operate independently to maintain revolutionary or religious ideals through performing acts in the arena of elections. For example in the presidential elections of 88 , they confronted a wide range of voters who believed that the elections was cheated; or dedicated parts of their activities or military units to media to handle the soft war.

Although these two approaches, military and the national medium, act in line with revolutionary and religious ideals, the national medium makes an attempt to absorb those who are directly or indirectly complaining about the current situation but do not show themselves as evident protestors on the street. It seems that despite influential feedback, seminaries and a range of the military in the national medium attempt to pay attention to this part of the community so as to they not let down their revolutionary ideals and religiosity.

In such situations the national medium attempts to observe both national interests as well as maintenance of revolutionary and religious ideals, while these two goals do not always overlap. Thus a kind of unwanted self-disturbance is created in the national medium communication process. Especially regarding the international affairs, relations with foreign countries and cultures such discrepancies become prominent. Since non-governmental media or those which are independent from the political-religious ruling system are not allowed, whatever is broadcasted by the national medium is the fruit of the Islamic regime of Iran.

More importantly, there is no institution independent from the regime in the country to criticize the activities by the national medium. Moreover there is no private broadcasting system that allows the national medium to avoid internalization of its self-disturbance through completions. Such a problem may provide many disadvantages from the national medium toward the public opinion and culture as follows:

1. The most optimistic consequence with such self-disturbance in the national medium is the complementary approach to the national medium by some audiences, i.e. the national medium audience put the national medium's programs next to their media selections to be informed of the news, to watch some soap operas or movies among the plenty of other media programs in Persian speaking satellite channels.

2. Inability to provide a dominant pseudo-environment for a majority of domestic audience. Audience carefully uses media as though they enter a world which is virtually built. Normally such users despite of their critical views, enter a pseudo-environment built by the intended medium for the audience. Thus those audiences acquire, analyze and assess what they want through the environment. However this dominant pseudo-environment refers to audience as unwittingly or wittingly being influenced by the medium to regulate their affairs and relatively trust the programs.

3. Being among the causes of rumors in the community especially its turning into a public medium which may influence interpersonal or intergroup relationships; and consequently feed the thirst of the public opinion in news scarcity or vagueness and audience's awareness of the sensitivity or congruity of the situation with the rumor.

4. On the surface, as simply observed, the relation between people and the government could be briefly discussed. The public opinion confronts the national medium since this mass media is interpreted as a communicative mechanism between the political regime and people. In other words, whatever is distributed as a 
message is interpreted as a kind of advising dialogue by the regime in an unwritten rule. Thus reactions of people as the audience against the national medium may be interpreted a brief manifestation of legitimating or illegitimating. In other words the domestic or foreign audience sees the medium as a showcase. Thus the public acquaint with the religious and political system through this showcase. Considering the one-way performance of the national medium regarding the media communication, a message of political-religious power is sent to people. People generally must accept such a power system based on the absolute authority of the clergy. Feedback by the people in the process of political communication is not clear in the form of academic research.

5. If the audience is not satisfied with the national medium and reach saturation or vagueness regarding the political, social and religious culture of Iran (in addition to the use of other media that may be in political-ideological contradiction with Iran's state media) he/she does not always welcome the message sent by the national medium. They also attempt to not accept the filter of the message. If the national medium does not fill its distance with other foreign media consequently it seeks its own hallucinations. As a result it may provide a delusion of sociopolitical conspiracy on the mind of the audience.

6. Among the major problems is concerned with integrating national interests with revolutionary-religious values so that the national medium may provide doubts on the mind of the audience. This is due to the lack of overlapping national interests and revolutionary values. Politicians in one of these categories cannot attract the audience in the other category. They have always failed to provide an integration of these two important elements. Thus, the audience may come up with doubt and contradictions and cannot distinguish between these two elements so that gradually such a contradiction may be interpreted as vague for the national medium audiences, since acquiring knowledge of such feedback is replete with internal complexities and contradictions.

7. Since the national medium plays the role of a mediator between people and the regime, it has to fill the gap between the ruling system and people as quickest as possible. It is also assigned to facilitate the two-way relationship as much as possible. It should provide the ground for establishment of responsibility of the regime to people so that people also play the role of the sender of the message.

8. If the national medium is to discerningly send the message of the regime and does not allow for the reversed path of the message, the feedback provided by people will divert from reality. This occurs mostly by the expedient view of the revolutionary-religious ideals, while in the democratic systems defending the regime should be based on communicating with people by the regime. More importantly where people do not contribute to message production, opposed media, even for economic purposes, attempt to represent themselves as the voice of people which can attract the public. When the national medium suffers from self-disturbance and is unable to transform political, cultural, economic and social messages into the message of the national medium, inevitably it has to recourse to censorship while if it had enough knowledge the censorship could be lowered down. Therefore excessive censorship suggests a kind of distrust toward the audience. As a result of this distrust is manifested differently including in real feedback by the audience. (Political culture of congestion after the Islamic Revolution of Iran)

\section{Conclusion}

Overall the process of self-disturbance in the national medium of the Islamic Republic of Iran mostly arises from its media structure which does not accord with today's media requirements in the communication process. It is always influenced by personal tastes and needs and is inflicted with calamities in variety of ways which have hindered the organizational growth so that IRIB looks powered in some aspects whereas in some other grounds it is extremely frail; the majority of those working in the IRIB system suffer from an occupational identity crisis. As a result, after 36 years of the Islamic Revolution, the national medium, due to self-disturbance, is not able to act in line with national interests. The efforts made in this regard (revolutionary-religious values) do not even surpass a decade of creating a culture. Therefore, the national medium suffers from a crisis as well as a lack of content strategy which are mainly affected by the media structure of the national medium. The absence of rivals has questioned the systematic identity of IRIB and also has provided corruptions within the process of media communication. This has caused IRIB's inability to maintain its audience in the media competition arena where some are in opposition to the Islamic Republic of Iran.

\section{References}

Azdanlo, H. (1386). Familiarizing with fundamental concepts in sociology (2nd ed., p. 601). Publisher: Nie, Tehran, Iran.

Blick, R., \& Harwaldsen, E. (1378). Classification of concepts in communication (1st ed., p. 2). Massoud Aouhdi Publisher: Soroush, Tehran. 
Formation of public opinontoupdate Rumors. Ali asghar amini dehaghi. Retrieved from http://www.europeanjournal ofscientificresearch.com

Iranian cultural Homeland. Ali asghar amini dehaghi. Retrieved from http://www.americanjournal or scientificresearch.com

Nature of Iranian traditional nedia in political communication process. Ali asghar Amini dehaghi. Retrieved from http://www.lifesciencesite.com

Political culture of congestion after the Islamic Revolution of Iran. Ali asghar amini dehaghi. Retrieved from http://www.sciencepub.net/

\section{Copyrights}

Copyright for this article is retained by the author(s), with first publication rights granted to the journal.

This is an open-access article distributed under the terms and conditions of the Creative Commons Attribution license (http://creativecommons.org/licenses/by/3.0/). 